\title{
Mechanical and Morphological Characterizations of Carbon Fiber Fabric Reinforced Epoxy Composites Used in Aeronautical Field
}

\author{
Jane Maria Faulstich de Paiva*, Alexandre De Nadai dos Santos, \\ Mirabel Cerqueira Rezende ${ }^{c}$ \\ ${ }^{\mathrm{a} C a m p u s ~ d e ~ S o r o c a b a, ~ U n i v e r s i d a d e ~ F e d e r a l ~ d e ~ S a ̃ o ~ C a r l o s ~-~ U F S C a r, ~}$ \\ Rodovia João Leme dos Santos, $\mathrm{km} 110$ \\ Bairro Itinga CEP 18052-780, Sorocaba - SP, Brazil \\ ' Instituto Tecnológico de Aeronáutica - ITA, \\ São José dos Campos - SP, Brazil \\ ${ }^{\mathrm{C}}$ Divisão de Materiais - AMR, Instituto de Aeronáutica e Espaço - IAE, \\ Comando Geral de Tecnologia Aeroespacial - CTA, \\ São José dos Campos - SP, Brazil
}

Received: May 25, 2009; Revised: August 18, 2009

\begin{abstract}
Carbon fiber reinforced composites (CFRC) have been used in aeronautical industry in the manufacture of different aircraft components that must attend tight mechanical requirements. This paper shows a study involving mechanical (flexural, shear, tensile and compressive tests) and morphological characterizations of four different laminates based on 2 epoxy resin systems $\left(8552^{\mathrm{TM}}\right.$ and $\left.\mathrm{F} 584^{\mathrm{TM}}\right)$ and 2 carbon fiber fabric reinforcements (Plain Weave (PW) and Eight Harness Satin (8HS)). All laminates were obtained by handing lay-up of prepregs plies $\left(0^{\circ} / 90^{\circ}\right)$ and consolidation in an autoclave following an appropriate curing cycle with vacuum and pressure. The results show that the F584-epoxy matrix laminates present better mechanical properties in the tensile and compressive tests than 8552 composites. It is also observed that PW laminates for both matrices show better flexural and interlaminar shear properties.
\end{abstract}

Keywords: composites, epoxy, carbon fiber, mechanical properties

\section{Introduction}

Carbon fiber reinforced composites (CFRC) offer significant improvements over current conventional materials in aeronautical industry. Due to their attractive specific mechanical properties they have been used to manufacture different structural components as aileron, flaps, landing-gear doors and other structural parts.

Nowadays, CFRC are more usually processed using thermoset polymers, especially epoxy resins. Polymeric laminated composites present high strength-to-weight and stiffness-to-weight ratios when compared with metallic materials. However, these laminated composites are susceptible to damage loads because they are obtained by layer stacking with not strong interfaces between the plies. This characteristic explains the importance of improving the damage tolerance of these materials, for example, by modification of the resin system using adequate modifiers ${ }^{2,3}$. In this way, the mechanical properties characterization is an important tool to evaluate these materials.

Flexural, compressive and tensile strengths of fiber reinforced composites are usually performed to characterize polymeric composites due to the ease of specimen preparation and testing ${ }^{4,5}$. In flexural tests beams the small span-to-thickness ratio $(\mathrm{L} / \mathrm{h})$ are dominated by shear and beams with long spans fail in tension or compression. Knowing that deformation and failure of beams can occur under the influence of tension, compression and shear stresses, flexure tests are not recommended for design data determination ${ }^{4,6}$. However, flexural test is an important tool for optimization of process and evaluation of matrices and fiber-resin interface.

Interlaminar shear strength of fiber reinforced composite laminates is usually performed to characterize both fiber-matrix interfacial adhesion and also the effect of binder on the composite mechanical properties ${ }^{4,6,7}$. This test presents as an interesting advantage, that is, its ease specimen preparation that no demands gripping and end tabbing.

Under compression loading it is usually observed plastic deformation of the matrix and the buckling fibers tendency. In this case, the failure mechanism can involve microbuckling that frequently evolves to kink zones which leads to two-fracture plane formation. A laminate composite can also fail under axial compression by macroscopic shear of determined planes. In both case, it is important to consider that the failure in compression is dependent on the way that the loading is applied ${ }^{5,8}$.

Tensile tests can be used to verify specifications, quality assurance of project and failure mode analysis ${ }^{4,9}$. In polymeric composites characterization, the tensile tests are used for research and development and additionally to verify both strength and modulus to support the project of components, as shown in the literature for an epoxy composite $^{10}$.

This article presents experimental results of flexural, interlaminar shear, compressive and tensile strengths of four different manufac- 
tured laminates based on F584 and 8552 epoxy resin systems impregnated carbon fiber. Data evaluation and comparative testing were performed. Fractured surfaces resulted of the mechanical tests were evaluated by visual inspection and microscopic analyses.

\section{Experimental}

\subsection{Laminate molding}

The laminates were obtained by handing lay-up of pre-impregnated (prepregs) plies $\left(0^{\circ} / 90^{\circ}\right)$ and curing in an autoclave following an appropriate thermal cycle, with vacuum and pressure, according to the prepreg supplier instructions. The experiments considered 4 different laminate families based on 2 types of epoxy matrices (F584 and 8552) and 2 carbon fiber fabric reinforcements (PW -Plain Weave style and 8HS - Eight Harness Satin style). The used prepregs were supplied by Hexcel Composites Company. The studied laminates were named 584/PW, 584/HS, 8552/PW and 8552/HS.

The consolidation of the laminates in autoclave was performed by using vacuum bags in metal molds (plates) under pressure of $0.70 \mathrm{MPa}$. For both F584 and 8552 prepregs it was used a curing cycle with a heating rate of $2.5 \pm 0.2^{\circ} \mathrm{C} / \mathrm{min}$ until $177^{\circ} \mathrm{C}$, holding at this temperature for a minimum of 120 minutes. All processed laminates presented about $60 \%(\mathrm{v} / \mathrm{v})$ of carbon fiber reinforcement, determined according to ASTM D3171 ${ }^{11}$.

\subsection{Mechanical characterization}

\subsubsection{Flexural test}

The flexural tests were carried out in accordance to ASTM D790(6), method I (3-point loading), using a minimum of ten specimens $(80 \times 10 \times 4 \mathrm{~mm})$ for each laminate family. The tests were performed in an Instron testing machine at a constant cross-speed of $1.7 \mathrm{~mm} / \mathrm{min}$ at room temperature, using an appropriate device for flexural test. The flexural strength determination was based on Equation 1.1:

$$
\xi=\frac{3 \cdot P \cdot L}{2 \cdot b \cdot e^{2}}
$$

where:

$$
\begin{aligned}
& \xi=\text { flexural strength }, \mathrm{MPa} \\
& \mathrm{P}=\text { rupture load }, \mathrm{N} \\
& \mathrm{L}=\text { support span } \mathrm{m} \\
& \mathrm{b}=\text { width of specimen, } \mathrm{m} \\
& \mathrm{e}=\text { thickness of specimen, } \mathrm{m}
\end{aligned}
$$

\subsubsection{Interlaminar shear test}

The interlaminar shear tests (ILSS) were performed in accordance to ASTM D2344(12), using at least ten specimens (short beam: $24 \times 6.35 \times 4 \mathrm{~mm}$ ) and an appropriate device for shear test and employing an universal machine (Instron ${ }^{\circledR}$, model 4301). The interlaminar shear strength was calculated based on Equation 1.2:

$$
\tau=\frac{0,75 . P_{R}}{b . e}
$$

where:

$$
\begin{aligned}
& \tau=\text { interlaminar shear strength, } N / \mathrm{m}^{2} \\
& \mathrm{P}_{\mathrm{R}}=\text { rupture load, } \mathrm{N} \\
& \mathrm{b}=\text { width of specimen, } \mathrm{m} \\
& \mathrm{e}=\text { thickness of specimen, } \mathrm{m}
\end{aligned}
$$

\subsubsection{Compressive test}

The compressive tests were based on ASTM D3410 ${ }^{(13)}$ using ten specimens with dimensions of $139.7 \times 12.7 \times 2-3 \mathrm{~mm}$, for each
CFRC laminate. In this case, end-tabs of fiberglass laminates were used. The tests were carried out in an Instron testing machine, at room temperature, at a constant cross-speed of $1.27 \mathrm{~mm} / \mathrm{min}$ with a type IITRI fixture (developed by Illinois Institute of Technology Research Institute). The compressive strength was calculated using Equation 1.3:

$$
\kappa=\frac{P}{b \cdot d}
$$

where:

$$
\begin{aligned}
& \mathrm{K}=\text { compressive strength, } \mathrm{MPa} \\
& \mathrm{P}=\text { maximum load, } \mathrm{MN} \\
& \mathrm{b}=\text { width of specimen, } \mathrm{m} \\
& \mathrm{d}=\text { thickness of specimen, } \mathrm{m}
\end{aligned}
$$

\subsubsection{Tensile test}

The tensile tests were carried out in accordance with ASTM D3039(9) using a minimum of 20 specimens $(250 \times 25$ width $\times 2-3 \mathrm{~mm})$ for each laminate family. The specimens were prepared by bonding end-tabs of glass fiber/epoxy laminate. The tests were performed in an universal testing machine MTS, model 744, with hydraulic grip and MTS 632 12C-20 extensometer, at constant cross-speed of $1.3 \mathrm{~mm} / \mathrm{min}$, at room temperature. The tensile strengths were calculated by using Equation 1.4:

$$
\sigma=\frac{P_{\max }}{A}
$$

where:

$$
\begin{aligned}
& \sigma=\text { tensile strength, } \mathrm{MPa} \\
& \mathrm{P}_{\text {max }}=\text { maximum load, } \mathrm{N} \\
& \mathrm{A}=\text { average cross-sectional area, } \mathrm{m}^{2}
\end{aligned}
$$

\subsection{Microscopic analyses}

Microscopic analyses were performed aiming to identify the failure mode occurrence in the specimens tested. Firstly, 4 specimens of each laminate family were analyzed by stereoscopy in a Zeiss ${ }^{\circledR}$ equipment, model Stemi SV11. Scanning Electron Microscopy (SEM) was

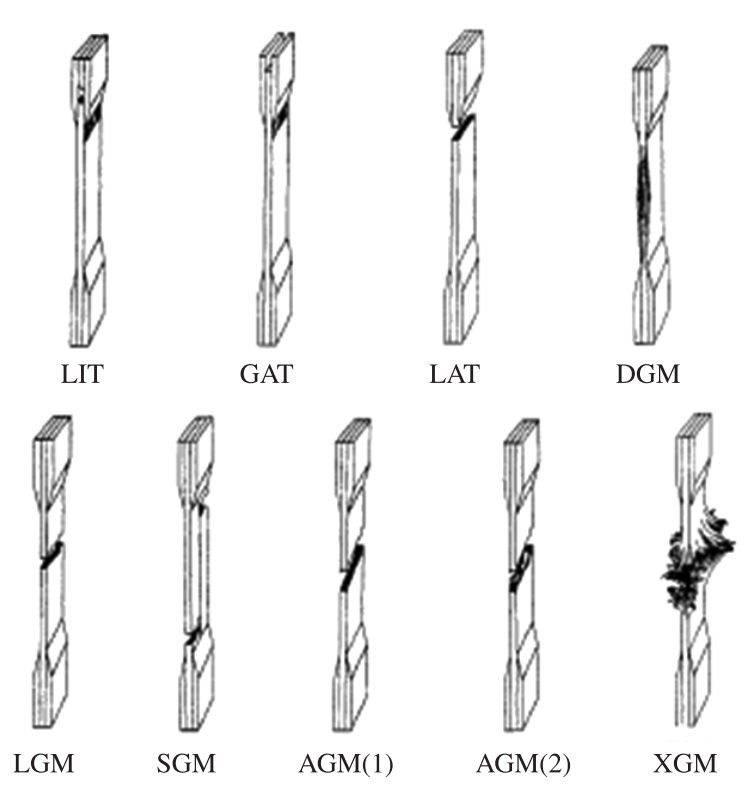

Figure 1. Representation of some typical failure modes and codes observed in tensile tests of composites ${ }^{(9)}$. 
Table 1. Codes related to failure modes(9).

\begin{tabular}{|c|c|c|c|c|c|}
\hline Failure Type & Code & Failure Area & Code & Failure Location & Code \\
\hline Angled & $\mathrm{A}$ & Inside grip/tab & I & Bottom & $\mathrm{B}$ \\
\hline Edge Delamintion & $\mathrm{D}$ & At grip/tab & A & Top & $\mathrm{T}$ \\
\hline Grip/tab & G & $<1 \mathrm{~W}$ from grip/tab & $\mathrm{W}$ & Left & $\mathrm{L}$ \\
\hline Lateral & $\mathrm{L}$ & Gage & G & Right & $\mathrm{R}$ \\
\hline Multi-mode & $\mathrm{M}(\mathrm{xyz})$ & Multiple Areas & M & Middle & M \\
\hline Long Splitting & S & Various & V & Various & V \\
\hline explosive & $\mathrm{X}$ & Unknown & $\mathrm{U}$ & Unknown & $\mathrm{U}$ \\
\hline Other & $\mathrm{O}$ & - & - & - & - \\
\hline
\end{tabular}

Table 2. Interlaminar shear, compressive and flexural strength values of the laminates studied.

\begin{tabular}{lccl}
\hline Laminates & $\begin{array}{c}\text { Flexural } \\
\text { Strength (MPa) }\end{array}$ & $\begin{array}{c}\text { Interlaminar shear } \\
\text { strength (MPa) }\end{array}$ & $\begin{array}{c}\text { Compressive } \\
\text { Strength (MPa) }\end{array}$ \\
\hline F584 / PW & $1288.5 \pm 45.4 *$ & $83.6 \pm 4.8$ & $681.6 \pm 16.8$ \\
F584 / 8HS & $1119.1 \pm 43.2 *--$ & $70.8 \pm 5.6$ & $728.8 \pm 30.5^{*}$ \\
8552 / PW & $921.7 \pm 48.9$ & $80.5 \pm 4.2$ & $656.4 \pm 17.2$ \\
8552 / 8HS & $873.2 \pm 35.7$ & $67.7 \pm 6.4$ & $668.2 \pm 20.1$ \\
\hline
\end{tabular}

* Result of a previous work (14)

also used to characterize shear tested specimens. A LEO equipment, model DSM 435, with variable pressure device was employed.

\subsection{Specimen inspection}

After the tensile tests, the specimens were photographed and the failure modes were classified in accordance with the type and the location of the damages attending the ASTM D3039 (Figure 1) 9 . Table 1 presents the codes depicted in Figure 1 and used to classify the failure modes of the studied laminates.

\section{Results and Discussion}

Table 2 presents the average results of interlaminar shear, compressive and flexural strength values of the studied laminates. Considering the flexural strength results obtained in accordance to ASTM D790(6), method I (3-point loading), it is observed that the PW reinforcement laminates show an increase of the flexural strength when compared with the 8HS laminate. This behavior is attributed to the PW fabric arrangement to provide a more resistance to the interlaminar shear effort and also a more adequate condition for mechanical anchorage of the polymeric matrix, favoring a stronger fiber-matrix interface.

A previous work ${ }^{14}$ shows flexural strength results for F584/PW and F584/8HS laminates of $1288.5 \pm 45.4 \mathrm{MPa}$ and $1119.1 \pm 43.2 \mathrm{MPa}$, respectively. These results show that the $\mathrm{F} 584^{\mathrm{TM}}$ (modified epoxy, medium toughness) resin gives a higher flexural strength for the laminate composite than the 8552 (toughened epoxy, amine cured) epoxy system. Comparing the tendencies presented in this study and that one reported in literature ${ }^{14}$, it is also verified that the PW laminate confers a better flexural strength performance for the processed laminates.

Comparing the determined flexural strength values for the F584/PW and F584/8HS laminates with that one reported by the prepreg supplier, approximately $1000 \mathrm{MPa}^{(15)}$, it is observed a good accordance.
Table 3. Tensile strength of the laminates tested.

\begin{tabular}{|c|c|c|c|}
\hline Laminates & $\begin{array}{c}\text { Tensile } \\
\text { Strength (MPa) }\end{array}$ & $\begin{array}{l}\text { Modulus } \\
(\mathrm{GPa})\end{array}$ & Failure Modes \\
\hline F 584 / PW * & $1185.4 \pm 51.4 *$ & $65.6 \pm 4.3^{*}$ & $\begin{array}{l}\text { LGB ( } 5 \text { specimens) } \\
\text { LGT ( } 3 \text { specimens) } \\
\text { LGM ( } 2 \text { specimens }) \\
\text { LIT ( } 2 \text { specimens })\end{array}$ \\
\hline F584 / 8HS * & $985.9 \pm 62.7 *$ & $71.5 \pm 0.3^{*}$ & $\begin{array}{l}\text { LGM (4 specimens) } \\
\text { LGB ( } 3 \text { specimens) } \\
\text { LIB ( } 3 \text { specimens }) \\
\text { LAB ( } 2 \text { specimens })\end{array}$ \\
\hline 8552 / PW & $840.7 \pm 40.0$ & $56.7 \pm 3.8$ & $\begin{array}{c}\text { LMT/B (6 specimens) } \\
\text { LIB (6 specimens) }\end{array}$ \\
\hline 8552 / 8HS & $779.8 \pm 54.7$ & $59.8 \pm 3.1$ & $\begin{array}{c}\text { LMT/B (6 specimens) } \\
\text { LIT (6 specimens) }\end{array}$ \\
\hline
\end{tabular}

Results of a previous work $^{(23)}$

Generally epoxy matrices applied in aeronautical components are based on DGEBA (diglycidyl ether of bisphenol-A) type with curing agent or hardener type 4,4'-diamino diphenyl sulfone (DDS). Epoxy resin modifications involve generally a trifunctional resin, as for example, tri-glycidil p-amino phenol modified with a thermoplastic, for example polysulphone of bisphenol-A (PSF) ${ }^{(16-18)}$. The modified epoxy resins are considered the state-of-art in thermoset matrix for laminate composites.

Schwartz ${ }^{1}$ reports flexural strength values for unidirectional carbon fiber (HMS high modulus) reinforced epoxy matrix of nearly $1034 \mathrm{MPa}$. Norwood ${ }^{19}$ shows flexural strength results of glass fiber fabric reinforced epoxy matrix of approximately $480 \mathrm{MPa}$. In a general way, these results are expected, considering the 2 different reinforcements.

Table 2 shows the average of the interlaminar shear strength results of F584/PW, F584/8HS, 8552/PW and 8552/8HS laminates in accordance with ASTMD 2344 ${ }^{[12]}$. These results show the influence of the reinforcement on the interlaminar shear strength values. It is clearly observed that the PW laminates present higher results than the 8HS ones. Probably, the PW fabric arrangement (warp:fill - 1:1) favored a more efficient mechanical anchorage of the resin on the carbon fiber reinforcement. These results agree with the interlaminar shear strength values reported by the prepreg supplier, approximately $70 \mathrm{MPa}^{[15]}$. These results show that both epoxy matrices present good performance in shear tests. In a previous work ${ }^{14}$, the authors show that the epoxy laminates based on F155/PW and F155/8HS present similar interlaminar shear strength values, $63.9 \pm 1.8 \mathrm{MPa}$ and $63.5 \pm 3.5 \mathrm{MPa}$, respectively. F155 matrix is an epoxy resin without specific modifiers. 
The compressive strength values and the standard deviations for F584 and 8552 laminates are close, excepted for the F584/8HS one determined in a previous study ${ }^{14}$. Comparing the influence of the 2 reinforcements it is verified the tendency of higher compressive strength values for the $8 \mathrm{HS}$ laminates. The same tendency is verified for the F584-epoxy based laminate when the 2 resin systems are compared. In the latter case, the higher compressive strength results are attributed to the modification of this epoxy matrix. Polymeric modifiers generally contribute to increase the fracture resistance of the epoxy system. This behavior is attributed to the formation of a second tough phase, which is initially miscible in the epoxy resin during the mixture formulation, but it separates at some point during the cure to forming 2 phases, a thermoplastic rich phase and an epoxy rich phase. This modification produces multiphase morphology able to dissipate the crack propagating energy which favors the toughening mechanisms ${ }^{[17]}$.

Table 3 shows the tensile strength results and the failure modes of the specimens tested. According to Table 3 the F584-epoxy matrix laminates present higher mechanical properties when compared to the 8552 resin system. This result allows concluding that the modifier used in the F584 system presents a good compatibility with both the F584 epoxy matrix and the carbon fiber, improving the F584 matrix toughness and the fiber-resin interface, respectively.

Considering the fabric arrangements, the PW type shows an increase of tensile strength when compared with 8HS type fabric for both matrices (F584 and 8552). However, the composites reinforced with 8 HS-fabric style show a tendency to increase the modulus value, mainly when combined with the F584 epoxy matrix. This

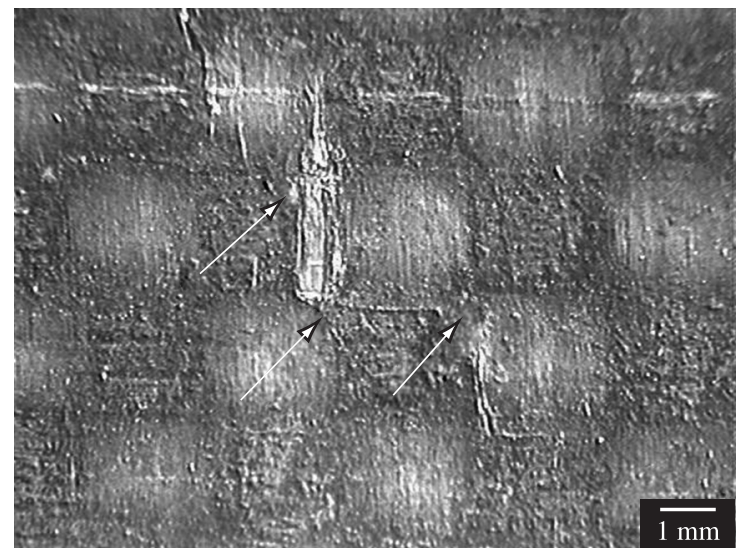

(a)

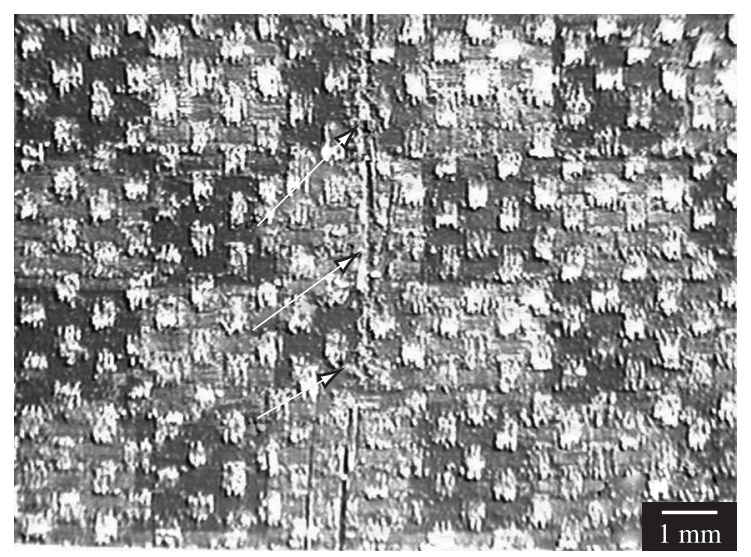

(b)

Figure 2. F584/PW laminate after flexural test: a) top side of the specimen, and $b$ ) bottom side of the specimen. behavior is related to the F584 matrix toughness which favors an appropriate elongation of strained carbon fibers, mainly for the 8HS arrangement.

All tensile strength results depicted in Table 3 attend the requirements for qualification and conformance assurance of aeronautical industry. The literature reports medium tensile strength values for composites reinforced with fabric $\left(0 / 90^{\circ}\right)$ of around $689 \mathrm{MPa}$ and a range of tensile modulus between 58 and $79 \mathrm{GPa}^{[24]}$. This literature ${ }^{1}$ reports that continuous unidirectional carbon fiber reinforced epoxy matrix presents tensile strength of approximately $1450 \mathrm{MPa}$ when tested at $0^{\circ}$-direction and $62 \mathrm{MPa}$ when tested at $90^{\circ}$-direction. The main advantage of fabric use as reinforcement in composite procesing is that the laminates have balanced properties in orientations $0^{\circ}$ and $90^{\circ}$. Meanwhile, the tensile strength and the modulus values of fabric-reinforced composites are lower than that observed for unidirectional fiber (tape) reinforced composites ${ }^{1}$.

Figures 2-4 show typical optical micrographs of the specimens fractured in flexure tests. All laminate families presented total failure of the tested specimens (as marked on the figures), independent of the different arrangements of the warp and fill of the carbon fabrics. The fractured regions of the tested laminates are in accordance with the requirements pointed in the standard ASTM D790, which make valid the performed flexural tests ${ }^{4,6}$.

The fractured regions of the F584/PW, 8552/PW and 8552/8HS laminates present any ductile characteristic diminishing the brittle aspect as observed in the previous work for F155 laminates ${ }^{14}$.

The tested specimens show on the top side of the specimen (load application side) (Figures 2a, 3a and 4a) that the cracks propagation

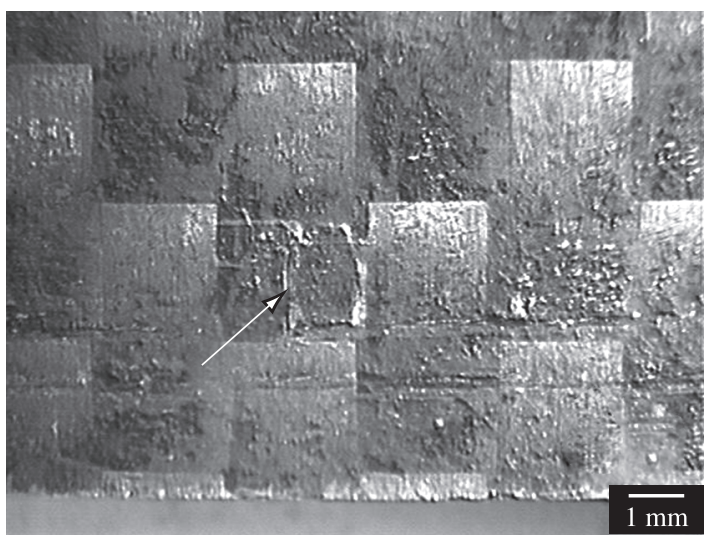

(a)

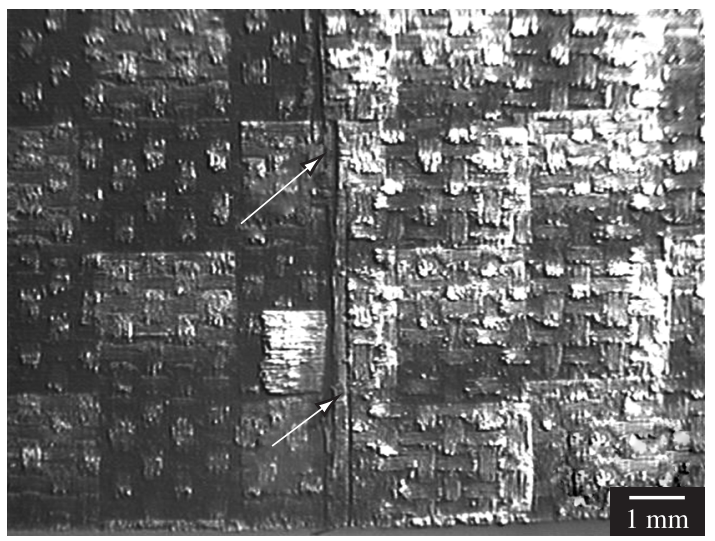

(b)

Figure 3. 8552/PW laminate after flexural test: a) top side of the specimen, and b) bottom side of the specimen. 


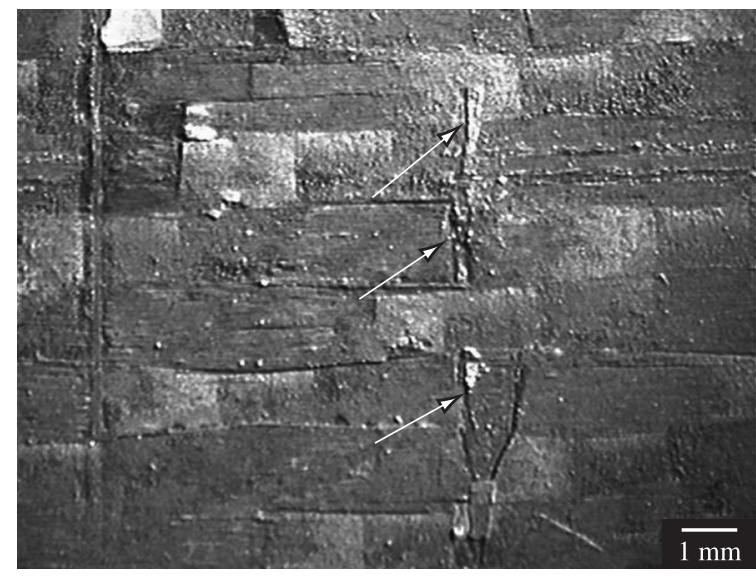

(a)

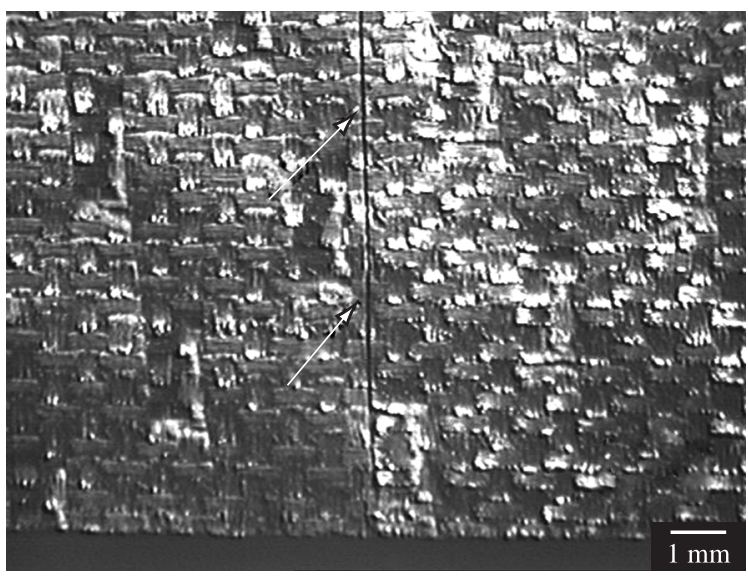

(b)

Figure 4. 8552/8HS laminate after flexural test: a) top side of the specimen, and b) bottom side of the specimen.

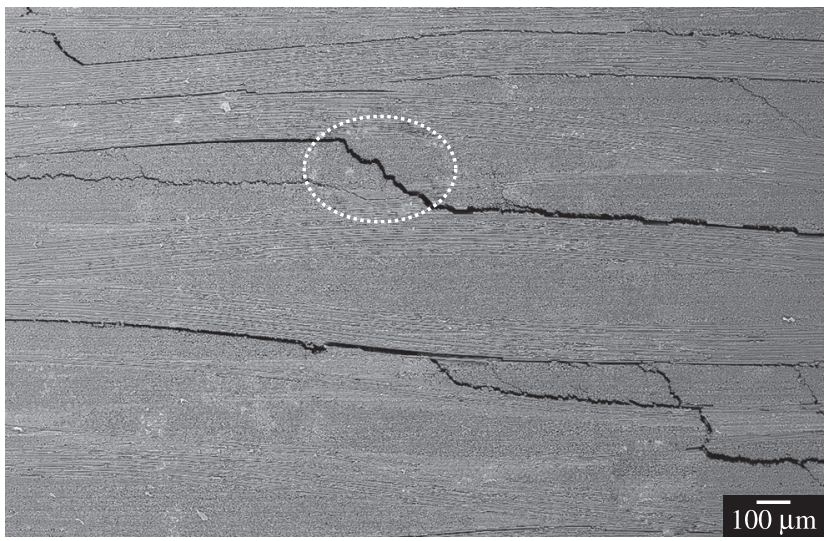

(a)

Figure 6. SEM of 8552/PW laminate after the interlaminar shear test.

follows preferable the fiber arrangement in the fabric, but the bottom side (flexural effort) (Figures $2 b, 3 b$ and $4 b$ ) shows a straight line, similar to brittle fractures. Figures 5-7 show SEM micrographs of the fractured specimens after the interlaminar shear tests. Independent of the damages, firstly it is observed that the specimen present a homogenous distribution of the reinforcement and the matrix. Focusing on

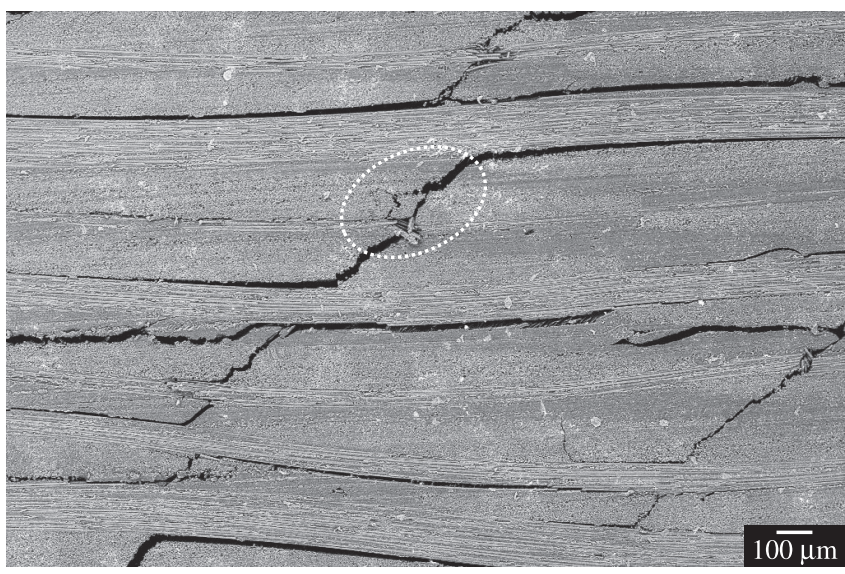

(a)

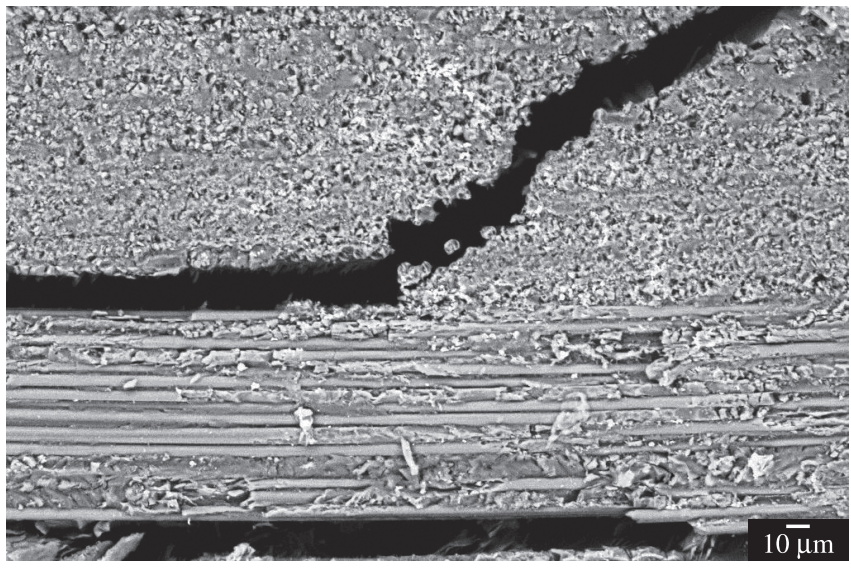

(b)

Figure 5. SEM of F584/PW laminate after the interlaminar shear test.

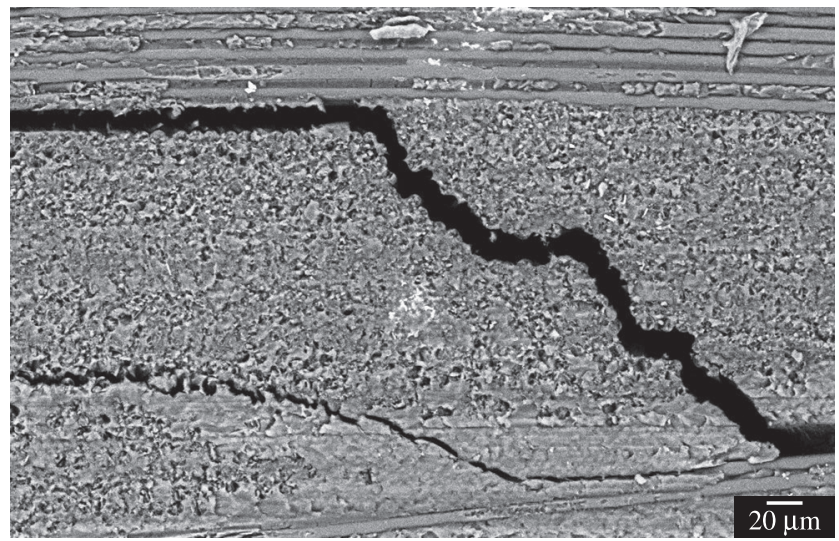

(b)

the damages, it is observed that all specimens show a typical failure mode by shear, with the interlaminar cracking in the middle part of the transverse region of the specimen. This behavior agrees with the literature ${ }^{20,21}$ and makes valid the performed test, which requires that the failure must reveal interlaminar failure mode. In these figures it is also observed delaminations among the layers that propagate through 


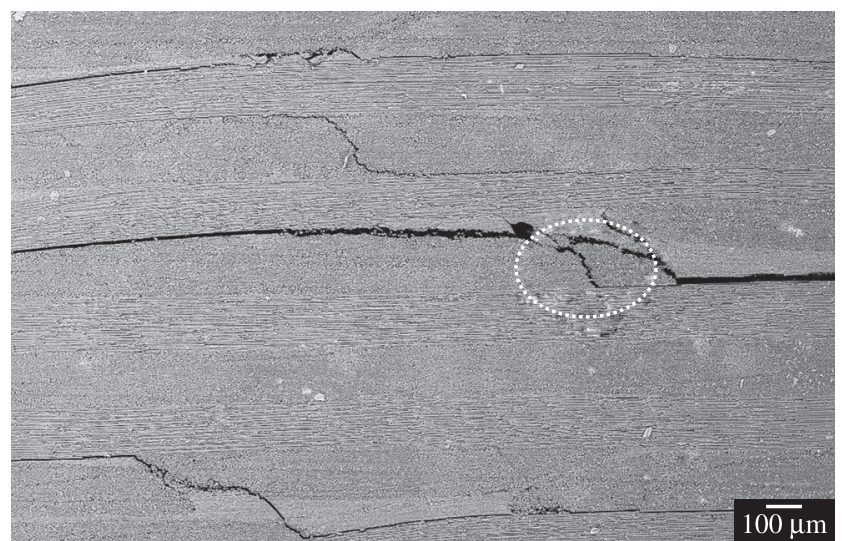

(a)

Figure 7. SEM of $8552 / 8 \mathrm{HS}$ laminate after the interlaminar shear test

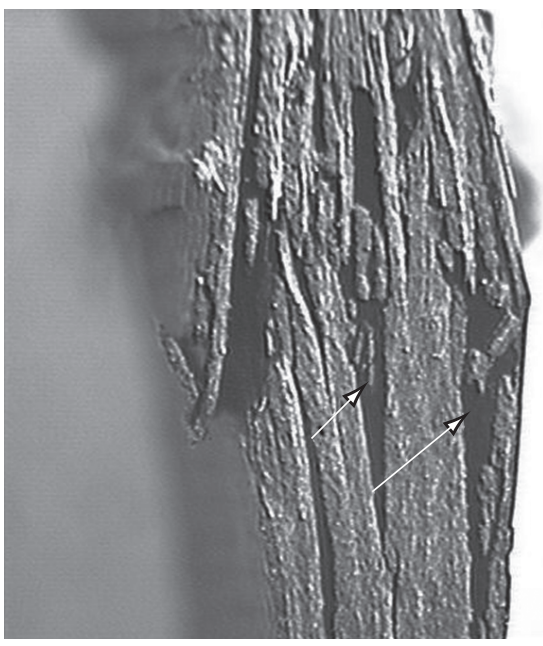

Figure 8. F584/PW laminate after the compressive test.

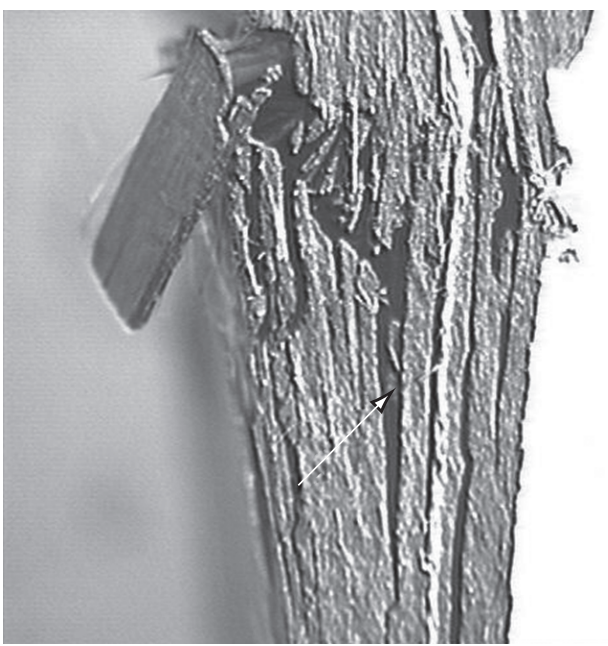

Figure 9. 8552/8HS laminate after the compressive test.

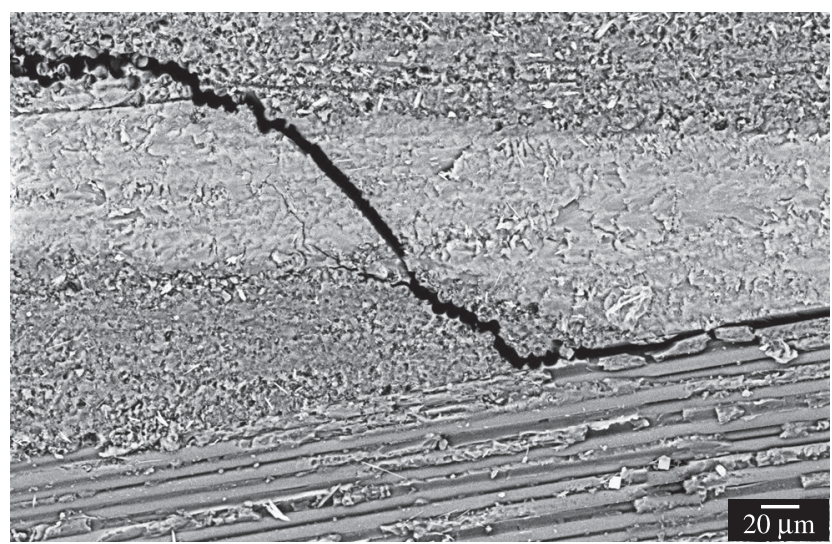

(b)

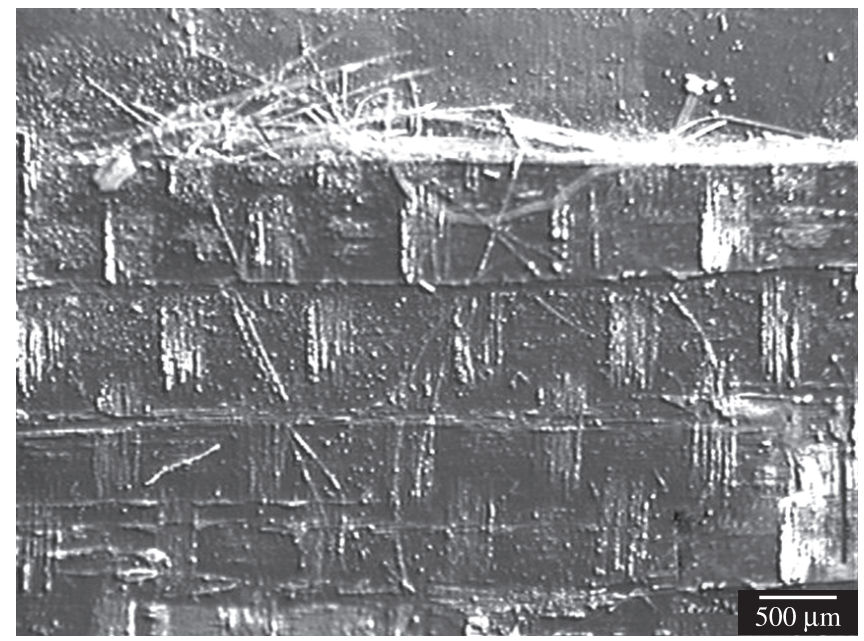

Figure 10. Typical aspect of a 8552/8HS laminate specimen after compressive test.

the specimen until the total rupture of the specimen. In a general way, it is observed that the crack propagation occurs preferable between the layers with the change of the crack propagation direction at the warp and fill crossing PW laminates present a larger number of cracks than the $8 \mathrm{HS}$ ones.

Figures 8 and 9 show typical micrographic aspects obtained in stereoscopic analyses of the specimens fractured in compressive tests. For all tested laminate families it is observed valid fracture modes. The fracture regions of tested laminates are in accordance with the literature $^{13}$. Figure 8 shows a typical failure mode observed for the F584/PW laminates, with the kink zones presence and the carbon fiber rupture $^{(22)}$. Figure 9 shows the failure mode observed for the 8552/8HS laminate specimens with microbuckling, kink zones and fiber rupture aspects. Figures 8 and 9 present also delaminations (showed by the arrows) that provoke the separation of the layers in the CFRC laminates. Figure 10 shows a fractured region of a 8HS specimen tested in compression emphasizing the carbon fibers rupture.

Figures 11 and 12 are representatives of specimens tested in tensile. These figures show valid failure modes classified in accordance with ASTM D3039 (Figure 1) and depicted in Table 1. After the tensile tests all specimen/tab bonded regions were evaluated and 


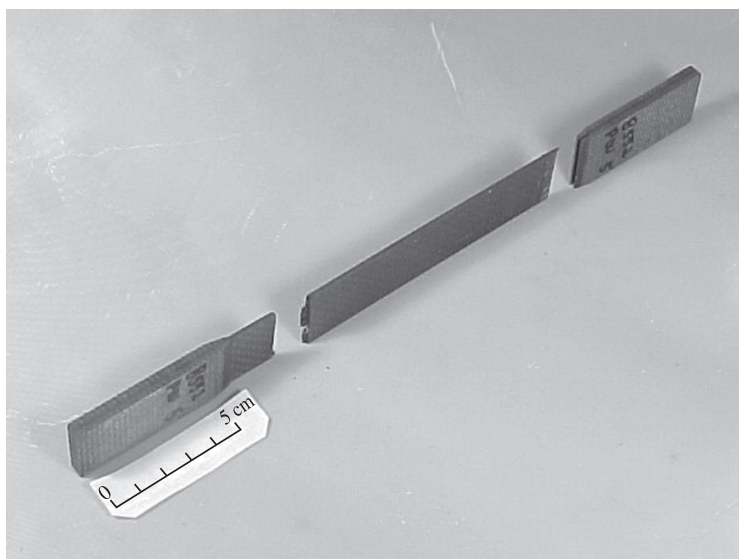

(a)

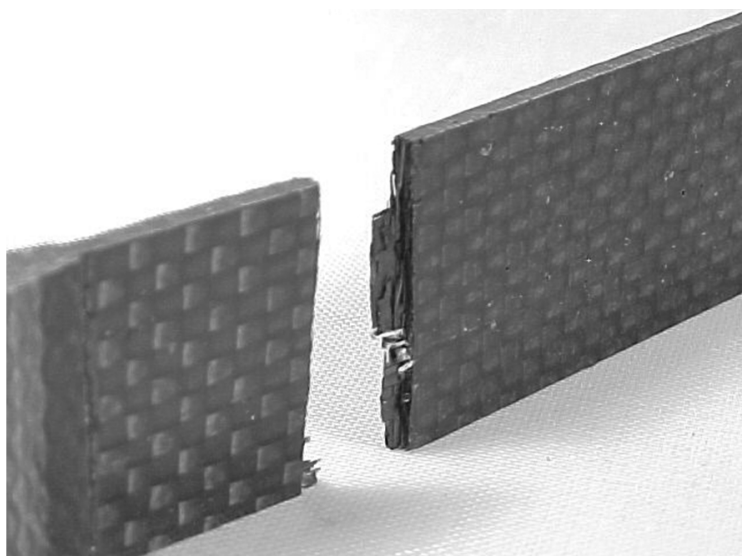

(b)

Figure 11. 8552/PW laminate: a) specimen tested; and b) detail of the failure mode type LMT/B (Lateral Multiple Top and Bottom).

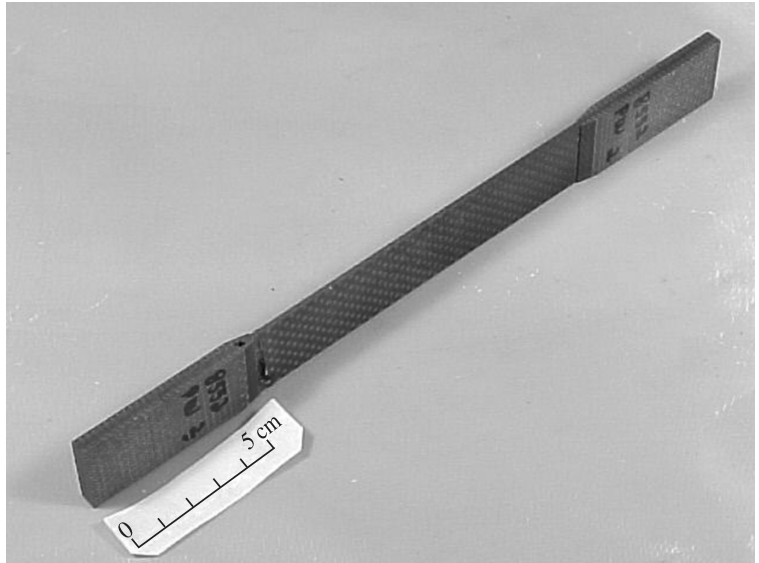

(a)

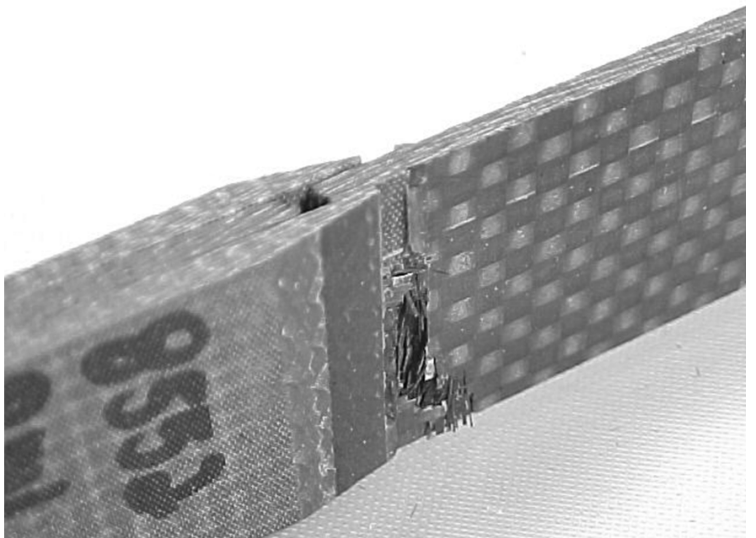

(b)

Figure 12. 8552/PW laminate: a) specimen tested; and b) detail of the failure mode type LIB (Lateral Inside grip/tab Bottom).

it was verified no occurrence of failure by shear and/or debonding in the interface between laminate/tab. It is observed that some specimens fractured near to the tab (Figure 12), as classified in ASTM D3039 and cited in Table 1, but no specimens showed adhesion failure. Thus, all failure modes were considered valid and the obtained experimental data could be used to calculate the tensile strength and the modulus of the tested specimens.

\section{Conclusions}

Flexural and interlaminar shear tests showed that the plain weave style (PW) of carbon fabric arrangement favored an increase of these mechanical properties when compared with the eight harness satin (8HS) type. This behaviour is attributed to the PW balanced arrangement and also to the fact of this arrangement to favor a better fiber-matrix interfacial anchorage. In compressive tests it was observed a tendency of higher strength values for F584-epoxy based laminate. Tensile strength results showed also that the F584epoxy matrix laminates present higher mechanical properties when compared to the 8552 composite laminates. These results are attributed to the F584-epoxy matrix modification which favored a better compatibility with the carbon fiber reinforcement and a higher F584 matrix-toughness.
For all performed mechanical tests, the respective failure modes were considered valid according to the literature and also to the technical standard of aeronautical industries.

\section{Acknowledgements}

The authors acknowledge the financial support received from FAPESP and CNPq (Process number: 301583/2006-3) and also the companies Hexcel Composites for supplying the used prepregs and Embraer for supporting the laminates preparation.

\section{References}

1. Schwartz MM. Composite Materials: Properties, Nondestructive Testing, and Repair. New Jersey, USA: Prentice-Hall Inc.; 1997.

2. Larsson F. Damage Tolerance of a Stitiched Carbon/Epoxy Laminate. Composites: Part A 1997; 28(A):923-934.

3. Soutis C, Smith FC and Matthews FL. Predicting the Compressive Engineering Performance of Carbon Fibre-Reinforced Plastics. Composites: Part A 2000; 31:531-536.

4. Carlsson LA and Pipes RB. Lamina compressive response. Experimental Characterization of Advanced Composite Materials. 2 ed. USA: Lancaster, Technomic Publishing; 1997. p. 81-91.

5. Matthews FL and Rawlings RD. Composite Materials: Engineering and Science. Great Britain: Chapman \& Hall; 2000. p. 168-205. 
6. ASTM D790. Standard Test Methods for Flexure Properties of Unreinforced and Reinforced Plastics and Electrical Insulating Materials. USA: American Society for Testing Materials; (1993). [CD-ROM].

7. Zhang Z, Liu Y, Huang Y, Liu L and Bao J. The effect of carbon-fiber surface properties on the electron-beam curing of epoxy-resin composites. Composites Science and Technology. 2002; 62:331-337.

8. Hull D and Clyne TW. An Introduction to Composite Materials. 2 ed. Great Britain: Cambridge University Press; 1996. p. 178-186.

9. ASTM D3039/D3039M-00. Standard test method for tensile properties of polymer matrix composite materials. USA: American Society for Testing Materials; (2004). [CD-ROM].

10. Mayer S, Cândido GM and Rezende MC. Influência do condicionamento ambiental na resistência à tração de compósitos de carbono/epóxi reparados. Polímeros 2003; 13(3):147-153.

11. ASTM D3171. Standard Test Methods for Fiber Content of Resin-matrix composites by Matrix Digestion. Philadelphia, PA: American Society for Testing and Materials; 1982. p. 122-124.

12. ASTM D2344. Standard Test Method for Apparent Interlaminar Shear Strength of Parallel Fiber Composites by Short-Beam Method. USA: American Society for Testing and Materials; 1984. p. 43-45.

13. ASTM D3410. Standard Test Method for Compressive Properties of Unidirectional or Crossply Fiber-Resin Composites. USA: American Society for Testing and Materials; 1987. p. 132-139.

14. Paiva JMF, Mayer S and Rezende MC. Evaluation of Mechanical Properties of Four Different Carbon/Epoxy Composites Used in Aeronautical Field. Materials Research 2005; 8(1):91-97.

15. Hexcel Composites. Resin systems for advanced composites. Catalog of Hexcel Composites, 2000. Available from: http://www.hexcel.com.
16. Tanoglu M, Robert S, Heider D, McKnigth SH, Brachos V and Gillespie Jr JW. Effects of thermoplastic performing binder on the properties of S2-glass fabric reinforced epoxy composites. International Journal of Adhesion \& Adhesives. 2001; 21(3):187-195.

17. Varley RJ, Hodgkin JH and Simon GP. Thoughening of a trifunctional epoxy system. Part VI. Structure property relationships of the thermoplastic toughened system. Polymer. 2001; 42:3847-3858.

18. Owen MJ. Thermosetting resins. Integrated Design and Manufacture using Fibre-Reinforced Polymeric Composites. Owen MJ, Middleton V and Jones IA (editors). USA, England: CRC Press LLC and Woodhead Publishing Limited; 2000.

19. Norwood LS. Fibre reinforced polymers. In: Handbook of Polymer Composites for Engineers. Hollaway L(editor). England: Woodhead Publishing Limited; 1994. p. 3-69.

20. Jang BZ. Advanced Polymer Composites: Principles and Applications. USA: ASM International; 1994.

21. Lafdi K and Wright MA. Carbon Fibers. In: Handbook of Composites. 2 ed. Peters ST (editor). Gret Britain: Chapman \& Hall; 1998. p. $190-199$.

22. Franco LAF. Análise Fractográfica de Compósitos Poliméricos Estruturais. São José dos Campos: Engenharia Aeronáutica e Mecânica, Área de Física e Química de Materiais Aeroespaciais, Instituto Tecnológico de Aeronáutica; 2003168 f. [Dissertação de Mestrado].

23. Paiva JMF, Mayer S and Rezende MC. Comparison of Tensile Strength of Different Carbon Fabric Reinforced Epoxy Composites. Materials Research 2006; 9(1):83-89.

24. MEP 15-022. Technical Specification of the Embraer (Empresa Brasileira de Aeronáutica). Brasil: 1999. p. 27-28. 